\title{
Active Flow Control in a Radial Vaned Diffuser for Surge Margin Improvement: A Multislot Suction Strategy
}

\author{
Aurélien Marsan, ${ }^{1}$ Isabelle Trébinjac, ${ }^{2}$ Stéphane Moreau, ${ }^{1}$ and Sylvain Coste $^{3}$ \\ ${ }^{1}$ Department of Mechanical Engineering, Université de Sherbrooke, Sherbrooke, QC, Canada J1K 2R1 \\ ${ }^{2}$ LMFA, Ecole Centrale de Lyon, 36 Avenue Guy de Collongue, 69134 Ecully, France \\ ${ }^{3}$ Safran Helicopter Engines, Avenue Joseph Szydlowski, 64510 Bordes, France
}

Correspondence should be addressed to Aurélien Marsan; aurelien.marsan@usherbrooke.ca

Received 31 January 2017; Accepted 9 April 2017; Published 9 May 2017

Academic Editor: Yutaka Ohta

Copyright (C) 2017 Aurélien Marsan et al. This is an open access article distributed under the Creative Commons Attribution License, which permits unrestricted use, distribution, and reproduction in any medium, provided the original work is properly cited.

\begin{abstract}
This work is the final step of a research project that aims at evaluating the possibility of delaying the surge of a centrifugal compressor stage using a boundary-layer suction technique. It is based on Reynolds-Averaged Navier-Stokes numerical simulations. Boundarylayer suction is applied within the radial vaned diffuser. Previous work has shown the necessity to take into account the unsteady behavior of the flow when designing the active flow control technique. In this paper, a multislot strategy is designed according to the characteristics of the unsteady pressure field. Its implementation results in a significant increase of the stable operating range predicted by the unsteady RANS numerical model. A hub-corner separation still exists further downstream in the diffuser passage but does not compromise the stability of the compressor stage.
\end{abstract}

\section{Introduction}

The stable operating range of centrifugal compressors is limited toward low mass flow rate by the onset of flow instabilities, either rotating stall or surge. This limitation is detrimental to the acceleration rate of the compressor that is a key performance parameter in particular for turboshaft engines and can also prevent operation at maximum efficiency which may lay at or close to the surge line. It is then of primary concern for turboshaft designers to better understand the surge inception process in centrifugal compressors and to develop design or control techniques in order to delay the surge.

In this context, the radial vaned diffuser appears to be a key component for surge inception in centrifugal compressors operating at high rotational speed. This was already pointed out by Came [1] in 1976 and has been confirmed by several studies since, but at this time the impeller was the most critical element of the stage from a performance point-of-view and the improvement efforts have then mostly focused on it.
In 1975 for a centrifugal compressor for automotive engine, Amann et al. [2] attributed the occurrence of rotating stall and surge to the radial vaned diffuser.

In 1994, Hunziker and Gyarmathy [3] have worked on a single-stage centrifugal compressor equipped with a radial vaned diffuser made of circular-arc vanes whose stagger angle could be adjusted. Maximum rotational speed is $22,000 \mathrm{rpm}$ and maximum pressure ratio is about 2,0. By analyzing the stability in various operating conditions and configurations using the criteria about the slope of the characteristics proposed by Greitzer in [4], the authors have concluded that the diffuser has a destabilizing influence at high rotational speed and for low mass flow rate which may explain the onset of surge. In particular, the diffuser entry zone is expected to play a major role since it has a stabilizing effect over the whole operating line but switches to a destabilizing effect at low mass flow rate.

In 2001, Wernet et al. [5] investigated the surge inception in the NASA-CC3 centrifugal compressor equipped with the wedge vane diffuser using digital particle imaging velocimetry. The design rotational speed is $21,789 \mathrm{rpm}$ for a design 
pressure ratio of about 4 . They have shown that the flow reversal at surge starts within the diffuser and then propagates upstream until forward flow is reestablished.

More recently, in 2010, Everitt and Spakovszky [6, 7] studied the onset of instabilities in a high-speed preproduction centrifugal compressor stage used for large diesel engines. The design pressure ratio is 5 and the impeller tip Mach number is greater than one at design speed. The radial vaned diffuser is made of airfoil vanes. Using the strategy first investigated by Hill IV [8] based on an isolated diffuser numerical model, the authors identify the growth of a flow separation at the leading-edge of the radial vaned diffuser as one of the necessary conditions for the formation of shortwavelength spike stall precursors.

In 2014, Bousquet et al. [9] studied a 2.5 pressure ratio subsonic centrifugal compressor stage designed by LiebherrAerospace Toulouse SAS and integrated it in an airconditioning system. It is composed of a backswept splittered unshrouded impeller and a radial vaned diffuser made of wedge blades. Design rotational speed is $38000 \mathrm{rpm}$. Based on the results of full-annulus 3D unsteady RANS simulations, the authors observed the growth of a flow separation at the leading-edge of the diffuser vane when moving the operating point toward the surge limit, in a similar manner to that previously reported by Everitt and Spakovszky [6, 7]. For that particular test case, however, this flow separation does not lead to an accumulation of vortical structure in the vaneless diffuser and the operating point remains stable until the flow separates at the leading-edge of the impeller blades [10].

Then, Buffaz et al. [11, 12] studied the onset of instabilities in a supersonic centrifugal compressor stage designed and built by Safran Helicopter Engines (SHE), both experimentally and numerically. The compressor was mounted on a $1 \mathrm{MW}$ test rig at the LMFA, École Centrale de Lyon, France, and detailed unsteady pressure measurements in the diffuser entry zone were performed. A full-annulus simulation of the surge inception was also conducted. The growth of a boundary-layer separation on the suction side of the diffuser vanes when moving the operating point toward the surge limit was again observed. This separation degenerates into a rotating stall finally leading to surge.

Other numerical investigations were conducted by Benichou and Trébinjac $[13,14]$ on another transonic centrifugal compressor designed and built by Safran Helicopter Engines (SHE). The test case is composed of a backswept unshrouded impeller and a splittered vaned diffuser. Pressure ratio is about 4 at a rotational speed of $40,000 \mathrm{rpm}$. The analysis of the flow field predicted by URANS simulations for an operating point near surge suggested that a boundary-layer separation on the suction side of the diffuser vanes was responsible for the surge inception.

Finally, the surge inception scheme proposed by Everitt and Spakovszky and based on the growth of a separation at the leading-edge of the diffuser vanes was found by Fujisawa et al. [15] in a centrifugal compressor of a turbocharger for marine diesel engines operating at low-speed. The study also showed the interaction between the diffuser leadingedge separation vortex and the tip leakage flow from the impeller.
Given the importance of the flow separation in the surge inception process for centrifugal compressor stages enlightened by these studies, the use of an active control technique aiming at controlling the flow separation within the diffuser is expected to be an effective way for delaying the surge. In particular, the boundary-layer suction technique has proven its effectiveness in case of axial compressors in order to either delay the surge or increase the blade loading [16-20].

In the next section, previous control strategies are reviewed.

\section{Previous Control Strategies}

Came [1] already mentioned in 1976 the possibility of designing efficient diffusers of smaller radial extent using boundary-layer suction. Still, there is no evidence yet in the literature of the interest of the boundary-layer suction in case of centrifugal compressors. The following aims at giving an overview of the other flow control techniques that have been applied to centrifugal compressors equipped with a radial vaned diffuser.

Botros and Henderson [21] give an extensive technology assessment of the surge control techniques for centrifugal compressors developed until 1993. The authors report the common use of 1D control technique based on the opening of a recycle valve when the surge is detected or on active control of the throttling element. Design methods are also given, as, for example, the use of a backswept impeller. The reduction of the diffuser exit width or specific designs of the diffuser inlet are also mentioned as means to influence the surge flow rate. Finally, a pioneering casing treatment developed by Amann et al. [2] in 1975 is reported. This treatment is applied to a centrifugal compressor whose surge is triggered by the occurrence of rotating stall within the radial vaned diffuser. It consists in a circumferential slot put at the impeller trailing edge and connected to an annular chamber. A significant decrease of the surge flow rate is reported. The effectiveness of the control is attributed to the uniformization of the pressure distribution over the circumference. Another technique relying on the same principle was proposed by Raw [22] in 1986. The so-called "porous throat diffuser" technique is based on the linking of the diffuser throats through slots connected to an azimuthal chamber. Again, the stabilizing effect is explained by the uniformization of the flow between all the diffuser passages, which may prevent the stall of any one diffuser vane before another one and then avoid the occurrence of rotating stall.

Later, Nelson et al. [23] managed to experimentally reduce the surge mass flow rate of an axicentrifugal stage by $1 \%$ using air injection into the throats of the diffuser passages.

Skoch also investigated the effectiveness of the air injection technique applied to the NASA CC3 compressor [24, 25] on the basis of the work of Spakovszky [26]. Injector nozzles were inserted first at the shroud of the vaneless diffuser space. It was found that the mere obstruction created by the injector nozzles at the shroud was sufficient to significantly decrease the surge mass flow rate and concluded that the benefit in diffuser stability came from the reduction of the incidence on the diffuser vanes. This conclusion was supported by hub-side 
injection experiments, whose conclusions were similar. The effects of the air injection technique in the NASA CC3 test case have been recently investigated numerically by Halawa et al. [27].

Other publications can be found in patents. A device is suggested by Schönenborn [28] based on boundary-layer suction on the suction face of the diffuser vanes. He also suggests that the bled flow could be used for the cooling of the turbine blades, for example. Another is proposed by Leblanc [29], the fluid being bled from the suction face of the diffuser vanes and then reinjected upstream in the vaneless diffuser space.

No detailed assessment of the potential of the boundarylayer suction technique applied to centrifugal compressor has been done yet. This is the objective of the present study.

\section{Test Case}

The test case is a centrifugal compressor stage designed and built by Safran Helicopter Engines (SHE), composed of a backswept splittered unshrouded impeller and a radial vaned diffuser. It is used as a rear compression stage in a helicopter engine. The flow at the impeller outlet is transonic. This compressor is installed in a $400 \mathrm{~kW}$ test rig of the DAEP Laboratory at the Institut Supérieur de l' Aéronautique et de l'Espace (ISAE), Toulouse, France. A complete description of the experimental test rig is available in [30].

For the compressor operating at its nominal rotational speed, previous work based on steady-state numerical calculations has shown the growth of corner stall within the semivaneless space of the diffuser when moving the operating point of the compressor toward the low mass flow rate [31]. This corner stall was supposed to limit the stability of the compressor stage and was also predicted by unsteady numerical simulations [32]. A boundary-layer suction technique had been foreseen and then studied in order to control the corner stall. According to steady-state numerical calculations relying on the mixing-plane approach, the suction led to a significant increase of the stable operating range of the compressor. But these promising results were challenged by unsteady numerical simulations [30]. The detailed analysis of the flow in the diffuser with suction has shown that the hub-corner separation was not completely removed by the suction, contrary to the prediction of the steady-state numerical model: a corner separation still existed in the diffuser downstream of the location of the initial boundarylayer separation, and the stable operating range was not extended. This result confirms the high influence of the unsteadiness on the flow in the diffuser entry zone, especially in centrifugal compressors with small radial gap between the impeller and the vaned diffuser [33]. The scrolling of the impeller blades in front of the diffuser vanes generates intense high pressure waves, in the same manner as already observed in another transonic Safran Helicopter Engines centrifugal compressor [34]. These high pressure waves are reinforced when crossing the diffuser throat. This generates intense instantaneous adverse pressure gradients that cannot be predicted by the steady-state numerical model and are supposed to provoke the boundary-layer separation. Figure 1

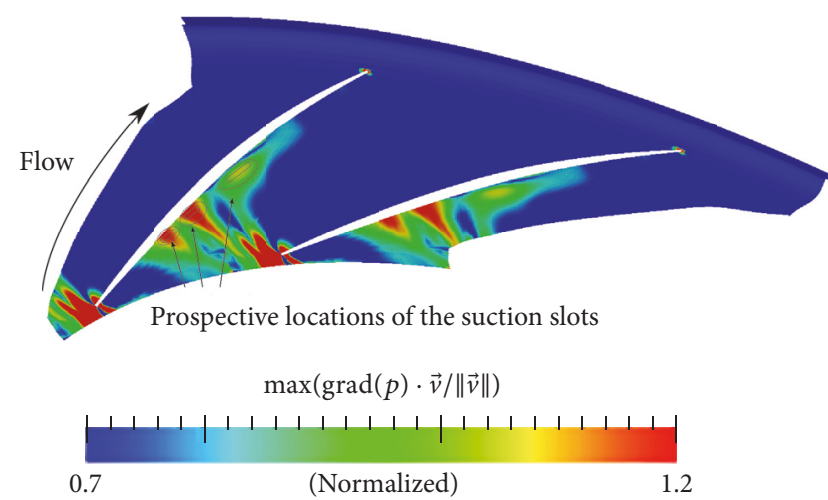

FIGURE 1: Maxima of instantaneous adverse pressure gradient, without control. Prospective locations of the suction slots.

shows the map of the maxima of the instantaneous adverse pressure gradient in the diffuser over one period.

Given that conclusion, the control strategy was adapted in order to take into account the unsteadiness. A multislot suction strategy was proposed but not evaluated. This strategy relies on three suction slots distributed along the diffuser suction side on the hub surface, at the locations of the maxima of the instantaneous adverse pressure gradient, as shown in Figure 1. The paper presents the results obtained by this multislot suction strategy.

\section{Numerical Setup}

Numerical simulations have been performed with the elsA software, developed by ONERA, the French aerospace laboratory [35]. This code solves the Reynolds-Averaged NavierStokes equations with a cell-centered finite volume method applied on multiblock-structured meshes [31,32]. The flow is considered fully turbulent and the effect of turbulence on the mean flow field is modeled thanks to the two variables $(k-l)$ turbulence model of Smith. The time integration is performed with a backward Euler scheme with implicit operators. Spatial discretization is achieved with Roe's second-order scheme and Harten's correction.

The mesh is the same as for the previous studies. It has been generated using the commercial meshing software Autogrid from Numeca. It counts 6,07 million points for one impeller-diffuser passage. The first cell height on the walls is 1 micrometer, which corresponds to a dimensionless wall distance $y^{+}$approximately equal to 1 along all solid surfaces. The impeller tip clearance is included in the numerical model and is meshed with a $\mathrm{C}-\mathrm{H}$ topology. Filets between the endwalls and the blades are included neither in the impeller nor in the radial vaned diffuser. Previous studies have shown that mesh independence in the diffuser is reached.

Unsteady numerical simulations of the flow within the compressor stage have been performed using the phaselagged assumption which is based on the Tyler and Sofrin relation and is also known as the chorochronic approach [3638].

In a previous publication [32], experimental unsteady pressure signals available in the diffuser entry zone have 


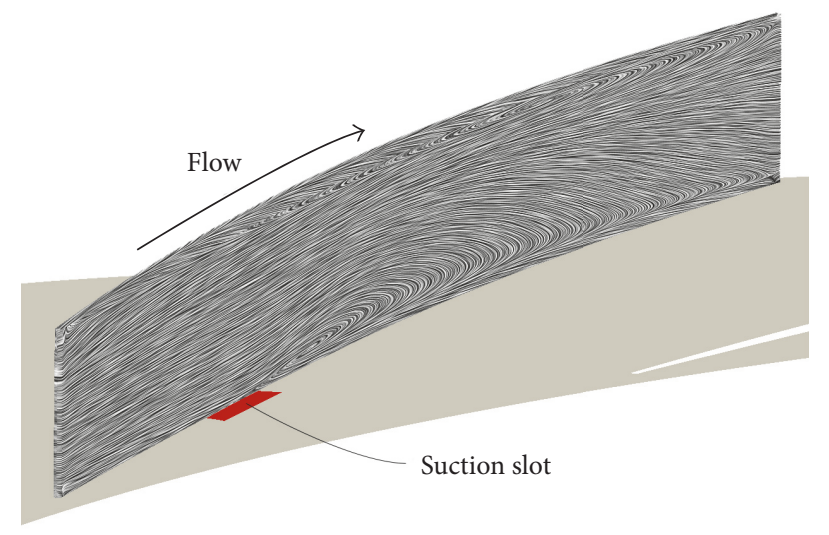

(a) Single-slot strategy

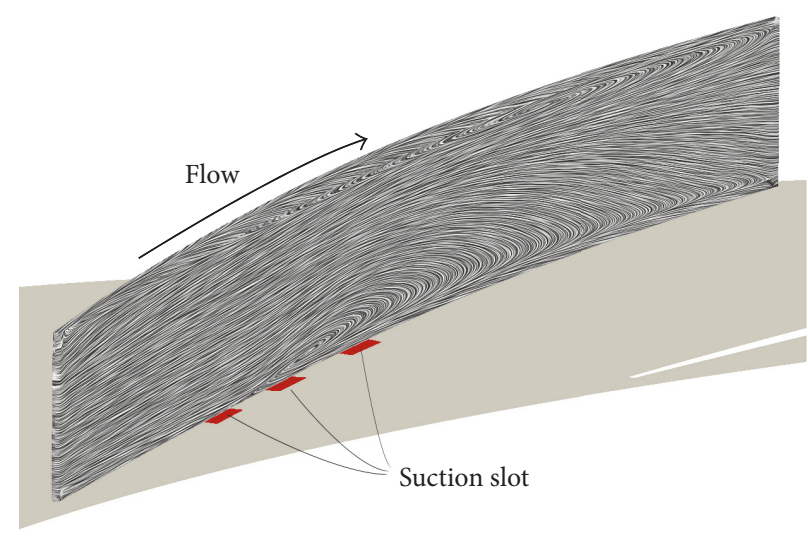

(b) Three-slot strategy

FIGURE 2: Suction strategies.

been compared with the unsteady numerical results (without suction). The comparison has ensured the capability of the numerical model at describing the flow in this compressor, even at near surge operating points.

For the present study, the numerical parameters have been kept the same except for the time step which is defined as

$$
\delta t=\frac{2 \pi}{\omega N_{R} N_{S} N q o}
$$

where $N_{R}$ and $N_{S}$ are the numbers of rotor and stator blades and $\omega$ is the rotational speed and Nqo is a parameter. For the base case, the Nqo parameter has been progressively doubled in order to check the time step convergence, starting from $N q o=20$ and ending at $N q o=160$. Regarding the convergence, Nqo was set to 60 for the single-slot suction case, as a compromise between the time step convergence and the computational time, and 80 for the multislot suction case.

The exit static pressure was set by prescribing a ratio between the value of the static pressure and the mass flow rate at the mesh exit plane. This allows computing the flow at a mass flow rate lower than the peak of the performance curve, which is necessary in order to reach the stability limit.

The boundary-layer suction was modeled by a surface mass-flux boundary-condition. The results obtained with this simplified model had been previously compared with those obtained by including the entire slot within the numerical model, using the chimera technique [39]. The relevance of the boundary-condition approach for analyzing the suction effect on the diffuser flow has been demonstrated: the boundary limit condition technique cannot describe the possible recirculation zone within the suction slot, but its effect on the main flow is consistent with the effect predicted using the chimera technique [31] and is more appropriate for the present study that does not deal with the important issue of designing an optimal suction slot.

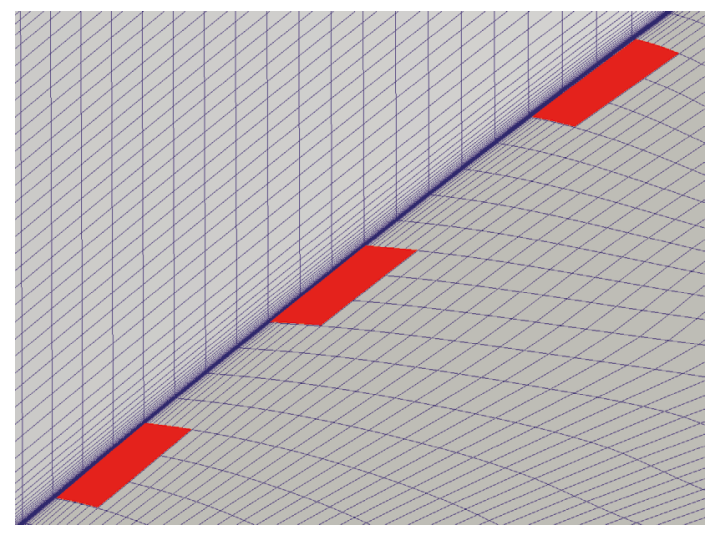

Figure 3: Numerical model of the three-slot suction effect by a boundary limit condition.

\section{Control Strategy}

Figure 2 shows the two suction strategies that are compared here. The single-slot strategy is the one that has already been studied and did not reach any improvement of the surge margin according to the time-dependent numerical simulations [30]. The three-slot strategy is the one which is under the scope of the present paper, the slots being located at the maxima of the instantaneous adverse pressure gradient.

Mass flow rate removed through the suction slots was chosen equal to 1 percent of the surge mass flow rate of the compressor without suction, which is consistent with the previous study, and the surface mass-flux was prescribed homogeneous all over the aspiration surface. In the case of the three-slot suction strategy, the surfaces of the three suction slots are slightly different from each other. The effect of suction is indeed modeled by a boundary limit condition and the possible area of the slots is constrained by the areas of the faces of the wall mesh (Figure 3). 0.32 percent of the surge mass flow rate is then removed through the first upstream slot, 0.33 percent through the second one, and 0.35 percent 
through the last downstream (the total being still equal to 1 percent of the surge mass flow rate).

\section{Results}

Given the strong unsteady interaction between the impeller and the diffuser for lowest mass flow rate operating points, the phase-lagged numerical calculation has required more than 25 impeller revolutions in order to reach the convergence for the last converged operating point with the three-slot suction strategy.

The limit of stability was searched by progressively increasing the prescribed ratio between the pressure and the mass flow rate at the outlet. It is important to notice that the limit of stability of the numerical model toward low mass flow rates has been reached for the base and the single-slot cases, but not for the three-slot case. Numerically stable operating points with the three-slot suction strategy could then exist at mass flow rate lower than the last plotted operating point.

\section{Performance}

Figure 4(a) shows the total-to-static pressure ratio of the compressor stage, plotted as a function of the standard mass flow rate at the impeller inlet. As indicated in the figure, no stable operating point has been found for the base case and the single-slot case below $\dot{m}_{R}^{\text {std }} \simeq 0.97$. On the contrary, it has been possible to reach the convergence for a much lower mass flow rate with the three-slot suction strategy. Both suction techniques result in an increase of the total-to-static pressure ratio of the compressor stage.

In order to analyze more precisely the effect of the suction on the performance of the compressor stage, Figures 4(b) and 4(c) show the main performance coefficients for the impeller and the radial vaned diffuser. Figure 4(b) shows the total-tostatic pressure ratio of the impeller plotted as a function of the diffuser inlet standard mass flow rate. Figure 4(c) shows the static pressure recovery coefficient in the different parts of the diffuser, also plotted as a function of the standard mass flow rate at the diffuser inlet. All contributions are calculated with respect to the kinetic energy at the vaneless diffuser inlet, that is, the impeller trailing edge, so that they can be added in order to find the static pressure recovery coefficient of the whole vaned diffuser.

The total-to-static pressure ratio of the impeller reaches a maximum at a mass flow rate which is close to the stability limit of the base case and the single-slot suction case. The three-slot suction strategy allows reaching a stable operating point for a mass flow rate lower than that of the total-to-static pressure ratio maximum. Indeed, the control should stabilize the operation of the diffuser.

The origin of the saturation of the total-to-static pressure rise of the impeller is not yet identified. It could be caused by a flow separation within the impeller or by a particular behavior of the tip leakage vortex, for example. Some future study should aim at clarifying the flow pattern within the impeller. Given the fact that the limit of stability of the base case is reached at the peak of the total-to-static pressure ratio of the impeller, the surge inception could be possibly explained by an interaction with a particular flow structure within the impeller which leads to the destabilizing of the diffuser hubcorner separation. Such an interaction between boundarylayer separation in the diffuser and the flow structure at the impeller outlet has already been observed [40].

The effect of the suction on the diffuser static pressure recovery process is visible in Figure $4(\mathrm{c})$. The $C_{p}$ of the semivaneless diffuser space is greatly increased by the control, with both the single-slot and the three-slot suction strategies. According to previous works which have identified the entry zone of the diffuser as a critical zone for the onset of instabilities [3, 41], the fact that the slope is steeper (negative slope) should have a stabilizing effect on the diffuser work. But the single-slot suction strategy does not improve the overall operating range despite the increase of $C_{p}$ in the semivaneless space. The only observation of the slopes to check a stability is thus proved to be insufficient.

Figure 5 shows the blockage coefficients calculated at the impeller trailing edge, the diffuser leading-edge, the diffuser throat and the diffuser trailing edge, near hub (between $0 \%$ and $30 \%$ of span-height), Figure 5(a), in the mid-span region (between $30 \%$ and $70 \%$ of span-height), Figure 5(b), and near shroud (between $70 \%$ and $100 \%$ of span-height), Figure 5(c). Blockage coefficient in a section $S$ is defined as

$$
B_{S}=1-\frac{\int_{S} \rho \mathbf{v} \cdot \mathbf{n} d S}{|\rho \mathbf{v} \cdot \mathbf{n}|_{\max }} .
$$

These coefficient are plotted for several operating points, as a function of the standard mass flow rate at the diffuser inlet.

In all sections except at the diffuser trailing edge, the blockage coefficients are very similar between the single-slot and the three-slot suction cases. In particular, there is no difference between the blockage curves at the diffuser throat. Finally, the only difference between the single-slot and the three-slot strategies is visible on the blockage coefficient at the diffuser trailing edge. The blockage decreases in the near hub region with the three-slot suction strategy. On the contrary, it increases in the near shroud region. This balance between the near hub and the near shroud blockage has been previously explained by the growth of a shroud-corner separation on the suction side of the diffuser vanes when the hub-corner separation is controlled [30].

\section{Flow Structure}

Figure 6 compares the skin-friction pattern on the suction side of the diffuser vanes for the three test cases. The compared operating points are those labeled in Figure 4(c) and have similar diffuser inlet standard mass flow rates, that is, similar diffuser inlet flow field conditions. The location of the suction slots are also shown. A hub-corner separation still exists with the three-slot strategy downstream of the last suction slot. Compared with the single-slot case, it is however translated downstream, and the control of the hubcorner separation is more effective. It now takes place far downstream of the diffuser throat, which could explain the 


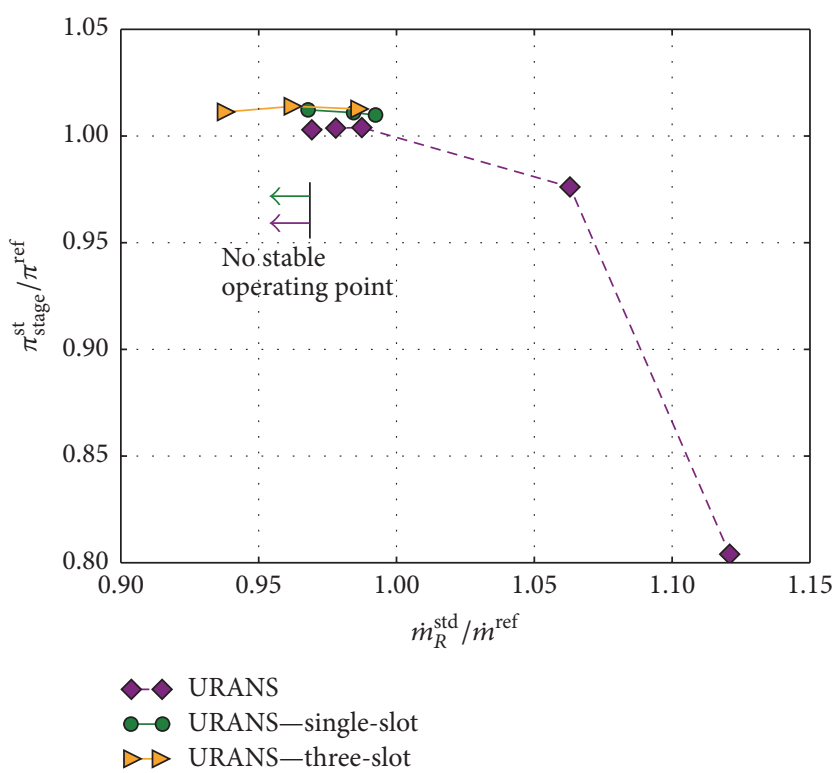

(a) Stage total-to-static pressure ratio

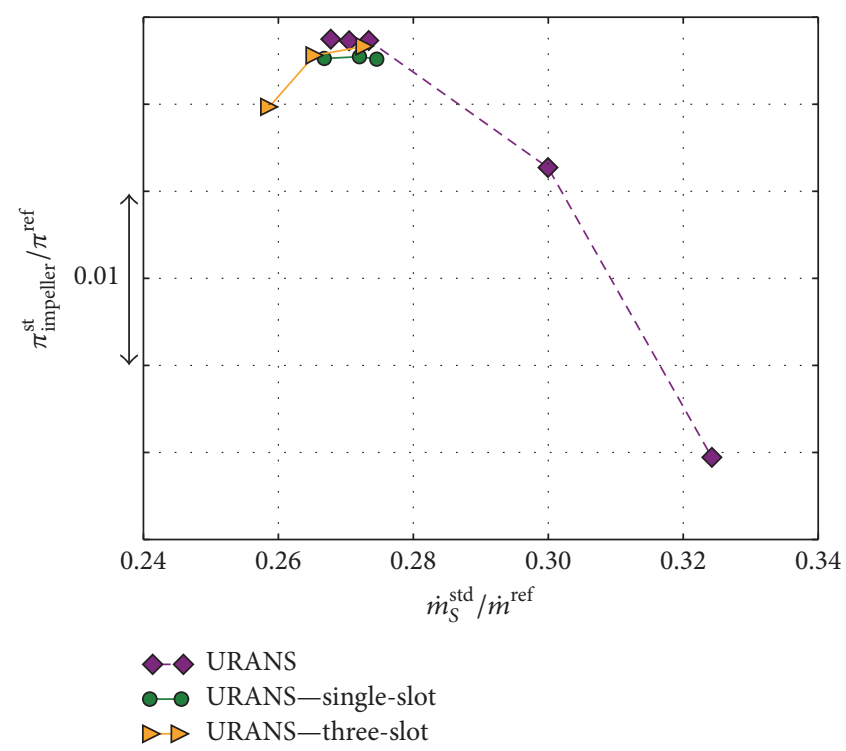

(b) Impeller total-to-static pressure ratio

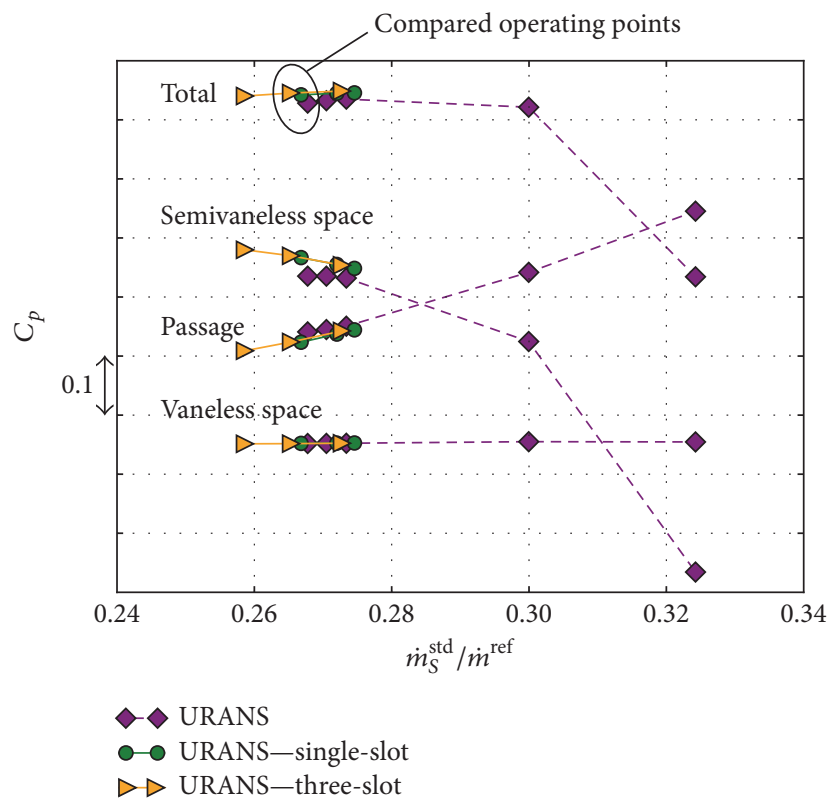

(c) Diffuser static pressure recovery coefficient

FIgURE 4: Performance of the compressor.

stabilizing effect of the three-slot suction case. As a consequence, the shroud-corner separation develops more. This explains the increase of the blockage near shroud previously mentioned, seen in Figure 5(c).

With the single-slot suction, the new location of the hubcorner separation downstream of the suction slot had been explained by the existence of intense instantaneous adverse pressure gradients [30]. In order to challenge that criterion for boundary-layer separation, Figure 7 shows the fields of the maximum of the instantaneous adverse pressure gradient in a plane located at 10 percent of span-height for the threeslot suction case. The location of the main saddle point of the skin-friction pattern in the corner is indicated by a black square. Here, the field of the maximum of instantaneous adverse pressure gradient is not modified by the three-slot suction effect, and the maxima are still located at the suction slots. The separation yet occurs downstream of the third maximum limit. A perspective of the present study could be to extend the third suction slot in order to cover the entire third maximum of instantaneous adverse pressure gradient, and verify if it could lead to a complete removal of the hubcorner separation.

Figure 8 shows a general overview of the flow structure in the radial vaned diffuser with three-dimensional streamlines calculated from time-averaged flow field. The threedimensional streamlines are colored by the value of the Mach 


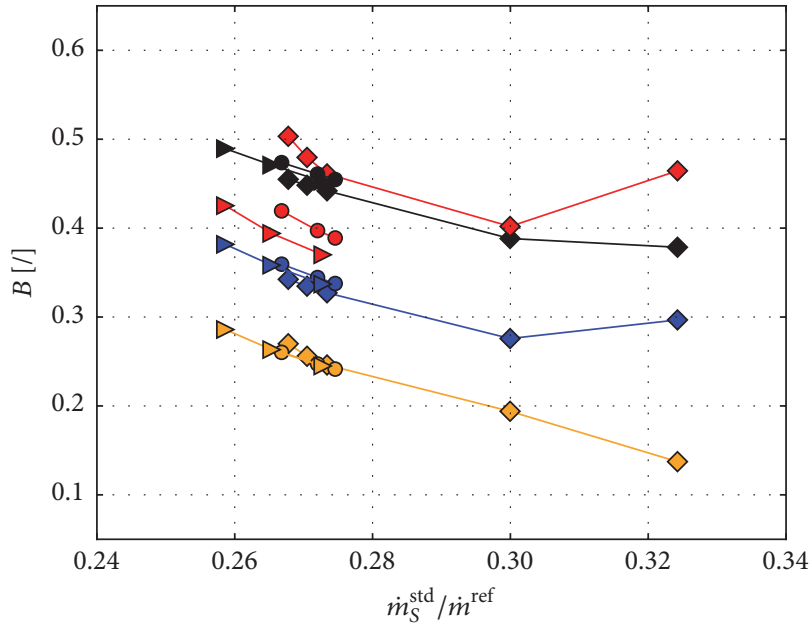

- Without suction

- Single-slot suction

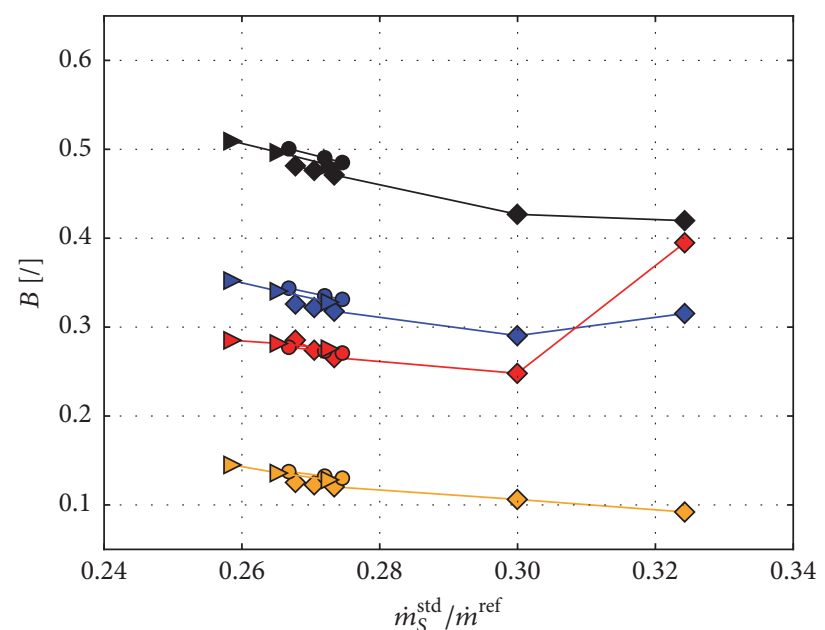

Impeller TE Diffuser LE

(b) $30 \%<h / H<70 \%$

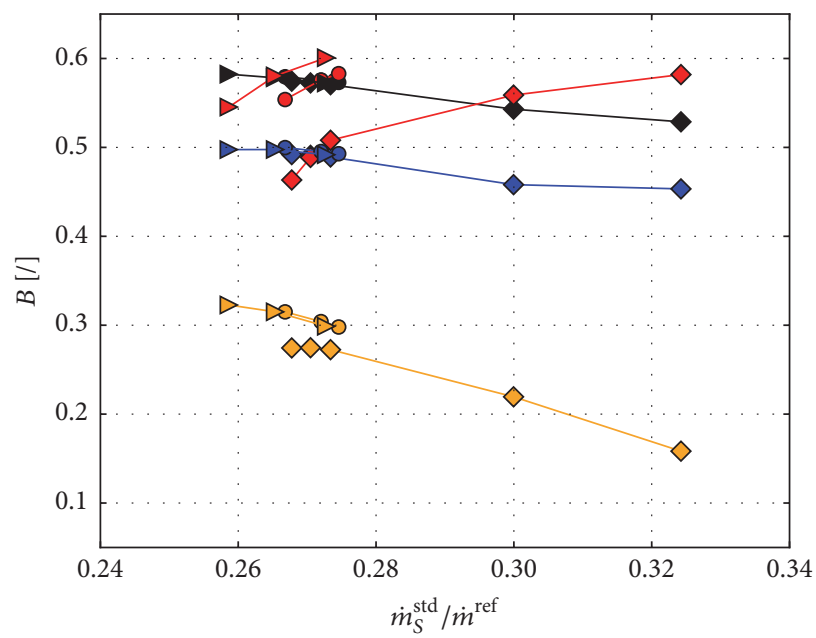

(c) $70 \%<h / H<100 \%$

Figure 5: Blockage coefficients in the diffuser.

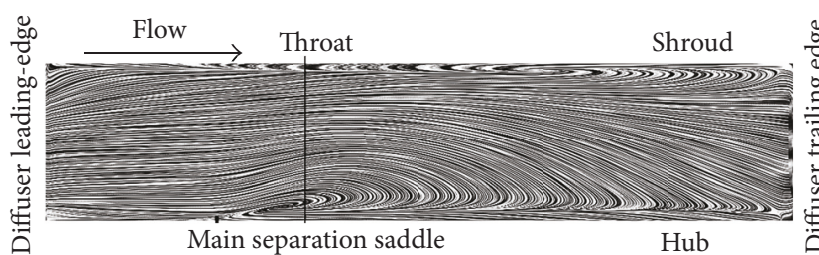

(a) Base case: $\dot{m}_{S}^{\text {std }} / \dot{m}^{\text {ref }} \simeq 0.269$

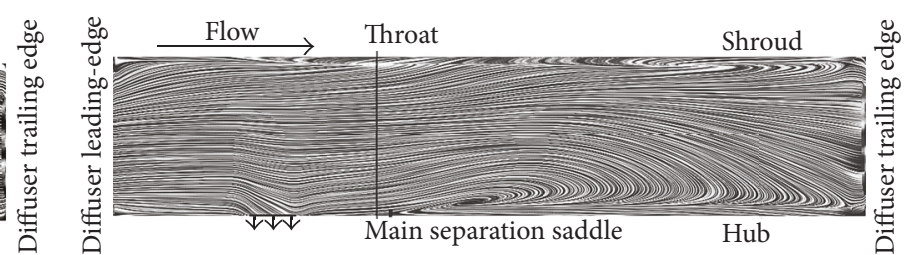

(b) Single-slot suction case: $\dot{m}_{S}^{\text {std }} / \dot{m}^{\text {ref }} \simeq 0.269$

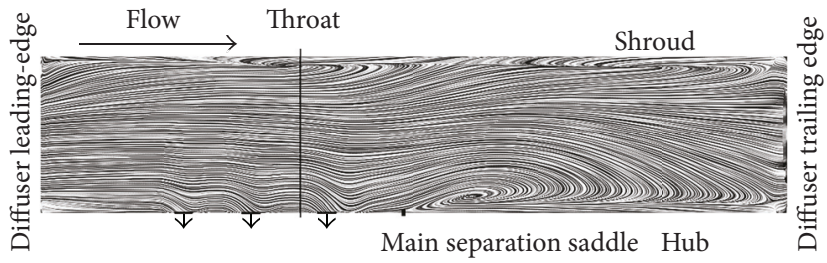

(c) Three-slot suction case: $\dot{m}_{S}^{\text {std }} / \dot{m}^{\text {ref }} \simeq 0.268$

FIGURE 6: Skin-friction on the diffuser suction side. 


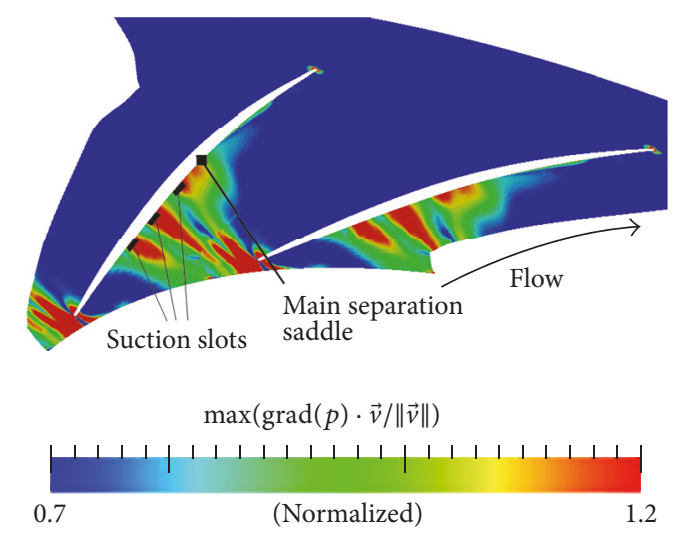

FIGURE 7: Maximum of instantaneous adverse pressure gradient-three-slot suction case.

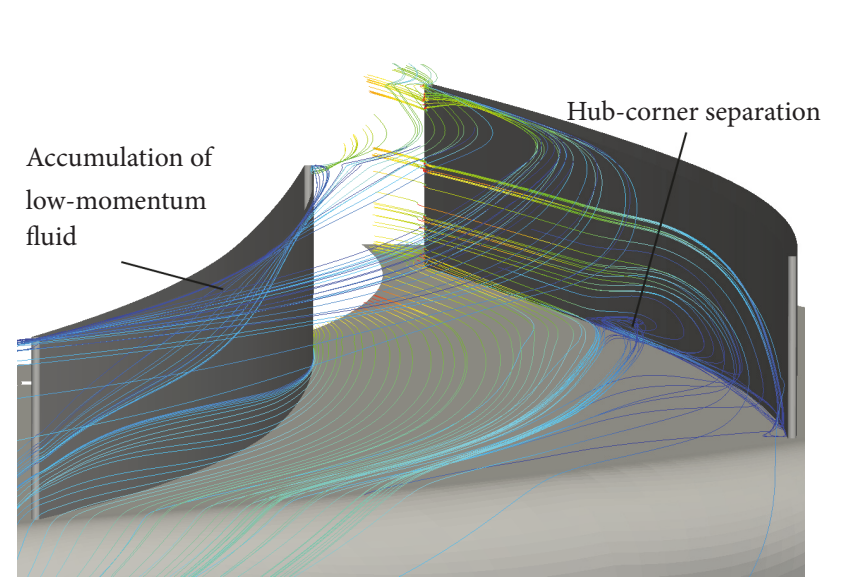

Absolute Mach number

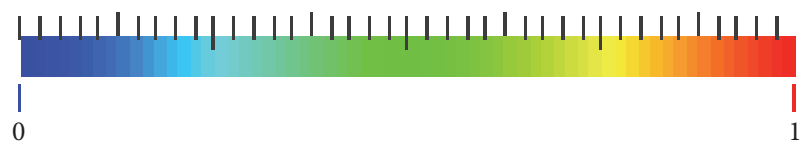

(a) Base case: $\dot{m}_{S}^{\text {std }} / \dot{m}^{\text {ref }} \simeq 0.268$

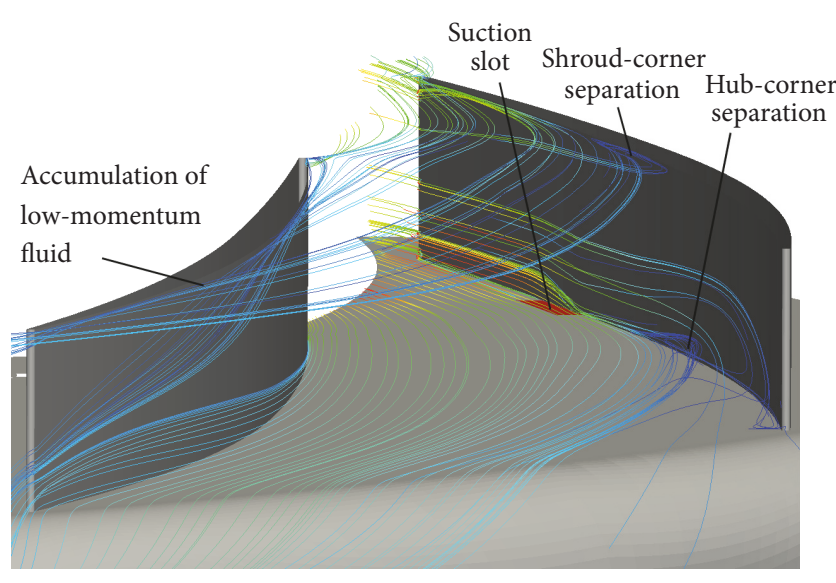

Absolute Mach number

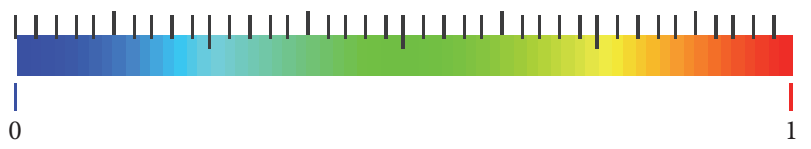

(b) Single-slot suction case: $\dot{m}_{S}^{\text {std }} / \dot{m}^{\text {ref }} \simeq 0.268$

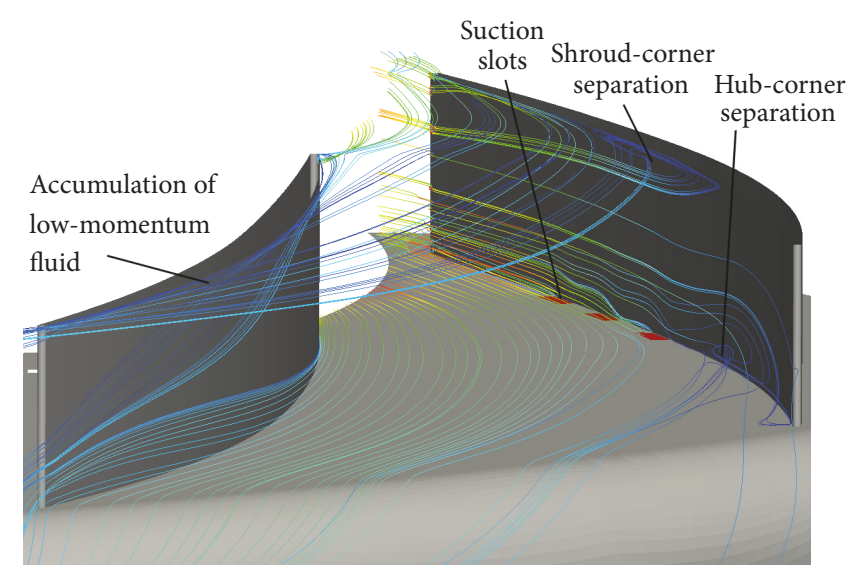

Absolute Mach number

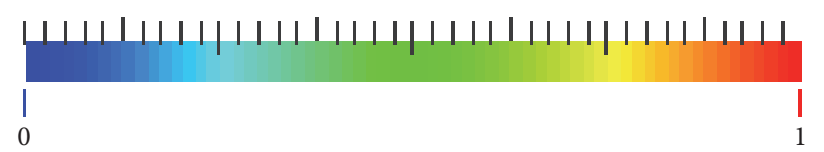

(c) Trislot suction case: $\dot{m}_{S}^{\text {std }} / \dot{m}^{\text {ref }} \simeq 0.269$

FIGURE 8: Three-dimensional streamlines. 

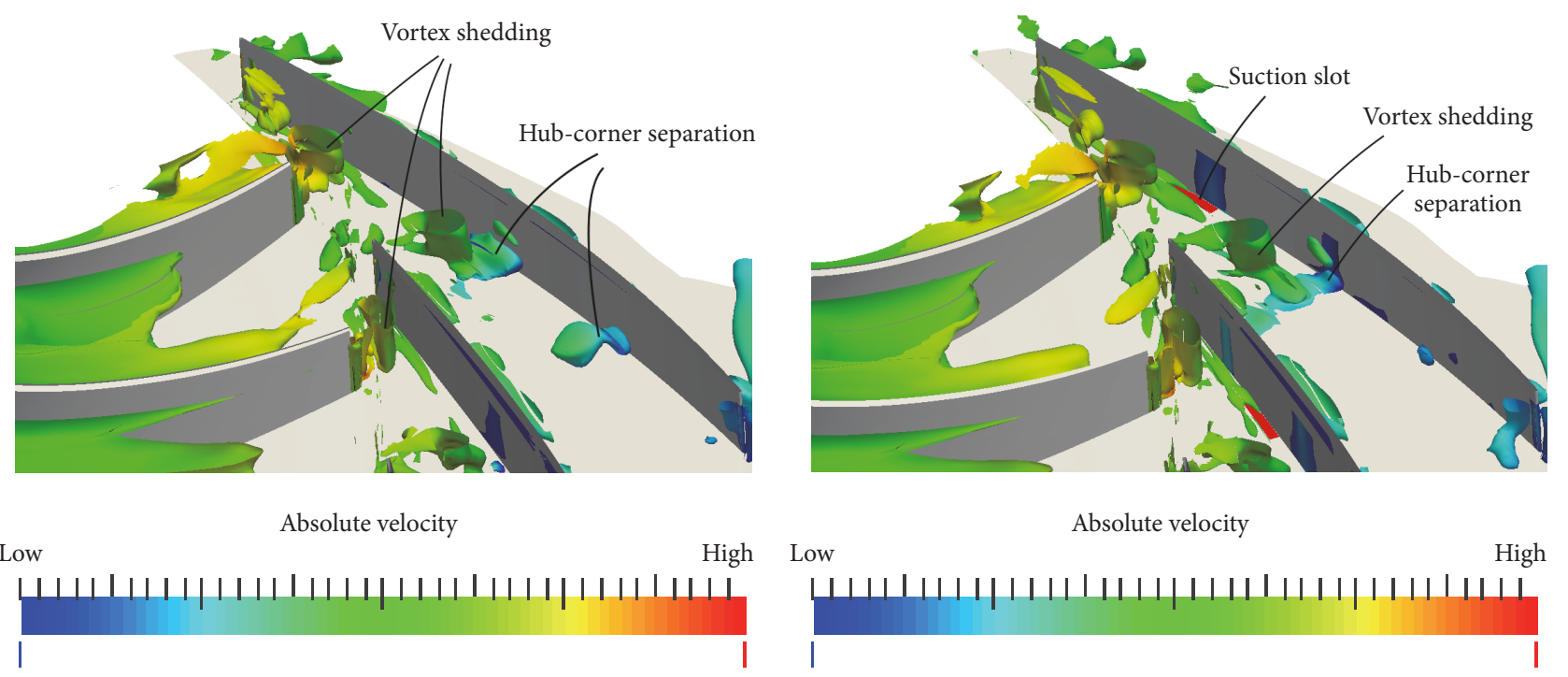

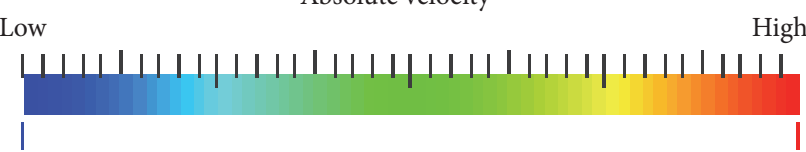

(a) Base case: $\dot{m}_{S}^{\text {std }} / \dot{m}^{\text {ref }} \simeq 0.269$

(b) Single-slot suction case: $\dot{m}_{S}^{\text {std }} / \dot{m}^{\text {ref }} \simeq 0.269$

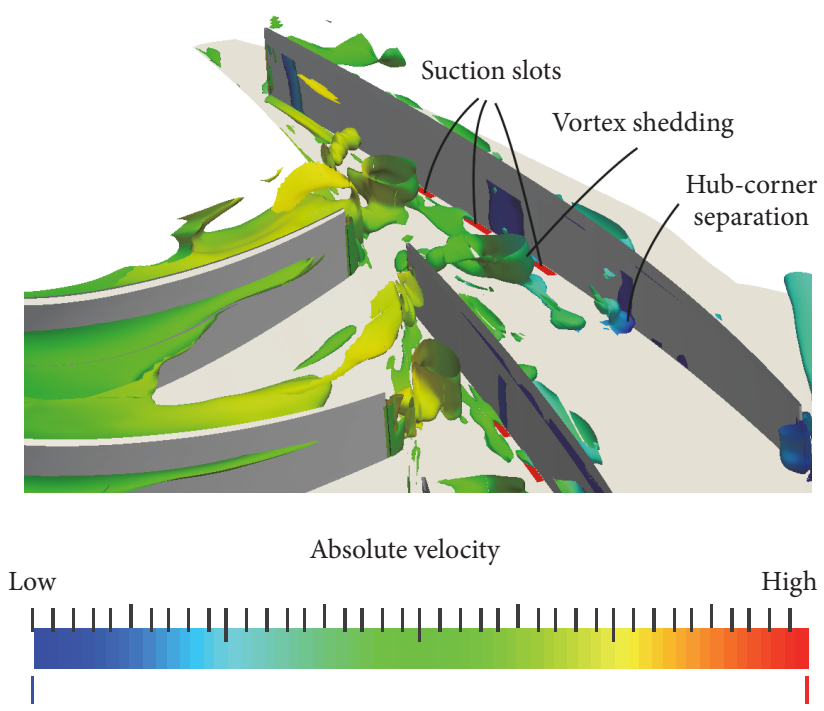

(c) Three-slot suction case: $\dot{m}_{S}^{\text {std }} / \dot{m}^{\text {ref }} \simeq 0.268$

FIGURE 9: Isocontours of $Q$-criterion in the diffuser colored by velocity: $Q=30$.

number along the streamlines. It stresses the translation of the hub-corner separation downstream under the effect of the suction and the growth of the shroud-corner separation, as previously mentioned.

In order to give more insight on the effect of suction, Figure 9 shows isocontours of $Q$-criterion in the diffuser computed from instantaneous flow fields for the three cases without and with control. The $Q$-criterion is a local measure of the excess of rotation rate relative to the strain rate [42]. It allows identifying the vortices as flow regions with positive second invariant of the velocity gradient tensor [43]. For clarity, isocontours are not plotted in the near-tip region, above $h / H=80 \%$.

The impeller vortex shedding and the hub-corner separation vortex are both visible in the three figures. For the base case, Figure 9(a), these two vortices merge together, which is expected to notably increase the size of the hubcorner separation vortex. With the single-slot control strategy, Figure 9(b), they still merge together but their interaction is decreased as the hub-corner separation is deflected. With the three-slot suction strategy, the interaction is barely visible given the chosen value for the isocontour.

This analysis stresses that the hub-corner separation development does not only result from the growth of the boundary-layers in the diffuser. It is also promoted by the interaction between the hub-corner separation vortex and other vortices like the impeller trailing edge vortex.

The vorticity transport equation that simplifies as

$$
\frac{\partial \Omega_{i}}{\partial t}+U_{j} \frac{\partial \Omega_{i}}{\partial x_{j}}=\underbrace{\Omega_{j} \frac{\partial U_{i}}{\partial x_{j}}}_{A}+\nu \frac{\partial^{2} \Omega_{i}}{\partial x_{j}^{2}}
$$




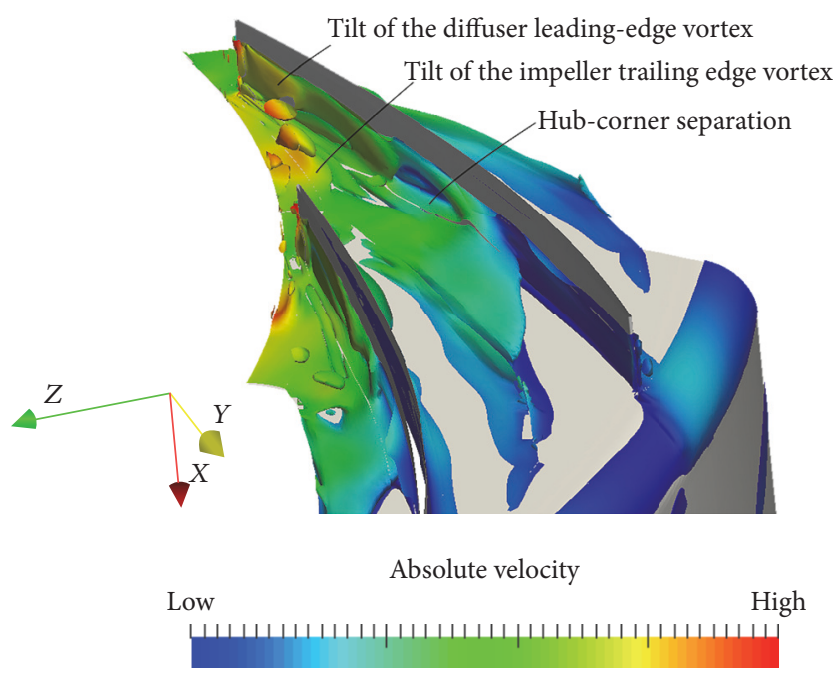

(a) Base case: $\dot{m}_{S}^{\text {std }} / \dot{m}^{\text {ref }} \simeq 0.269$
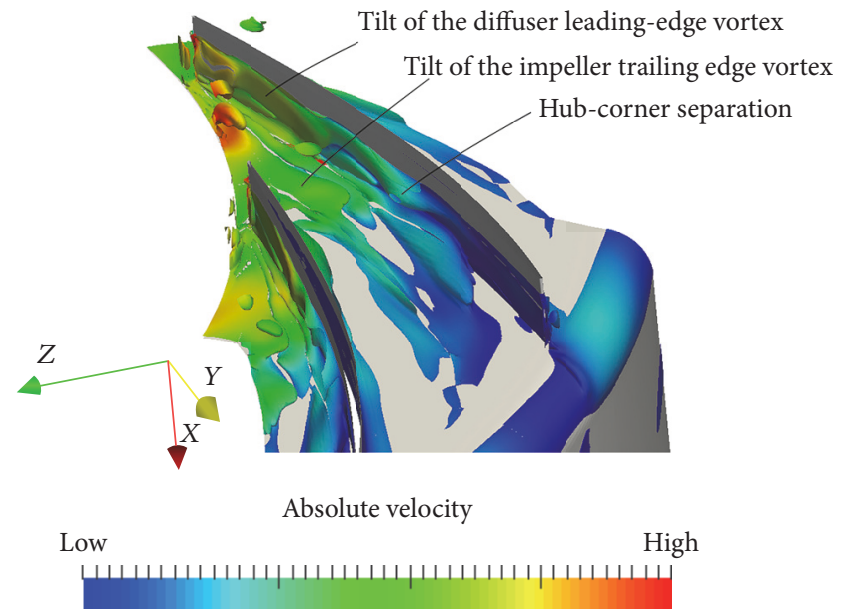

(b) Single-slot suction case: $\dot{m}_{S}^{\text {std }} / \dot{m}^{\text {ref }} \simeq 0.269$

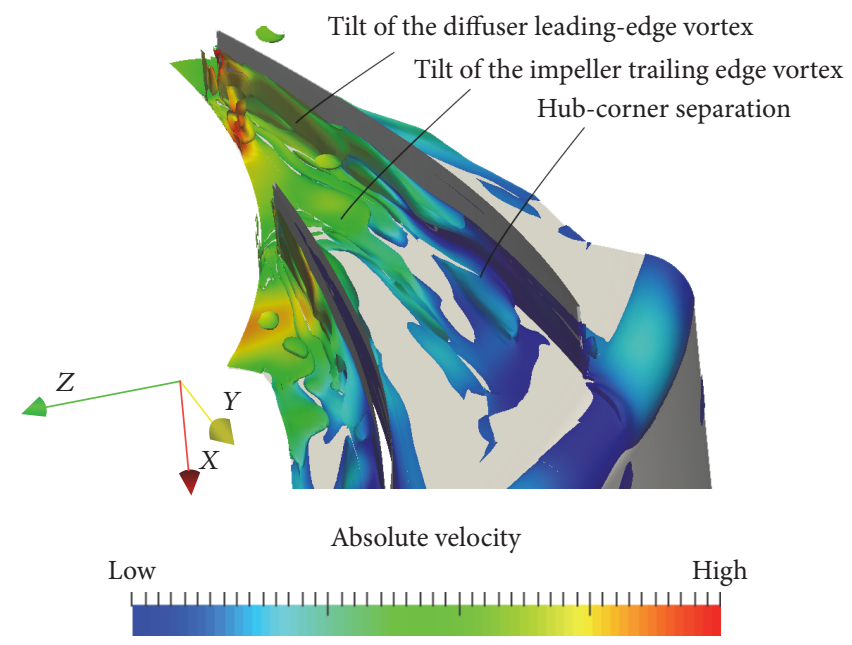

(c) Three-slot suction case: $\dot{m}_{S}^{\text {std }} / \dot{m}^{\text {ref }} \simeq 0.268$

FIGURE 10: Isocontours of tilt of the $\Omega_{x}$ vorticity component.

for incompressible and isotropic fluids subject to conservative body forces gives more understanding about the feeding of the hub-corner vortex by other vortices. In this equation, the term $A$ stands for the increase of the vorticity due to the tilt of vortices under velocity gradients. In case of a radial diffuser, the spanwise component of the vorticity can then feed the blade-to-blade vorticity under the effect of the spanwise velocity gradient. The impeller trailing edge vortex can then tilt and feed the hub-corner separation vortex thanks to the terms $\Omega_{x}\left(\partial U_{y} / \partial x\right)$ and $\Omega_{x}\left(\partial U_{z} / \partial x\right), x$ being the spanwise axis. In order to illustrate this phenomenon and to highlight the interaction between the impeller trailing edge vortex and the hub-corner separation vortex, Figure 10 shows isocontours of $\sqrt{\left(\Omega_{x}\left(\partial U_{y} / \partial x\right)\right)^{2}+\left(\Omega_{x}\left(\partial U_{z} / \partial x\right)\right)^{2}}$ for the three cases.

In Figure 10(a), a large structure is indeed visible near the hub surface and in the middle of the diffuser passage. It corresponds to the tilt of the foot of the impeller trailing edge vortex that flows into the hub-corner separation and contributes to its growth. The hub-corner separation is also clearly visible in the figure, since the hub-corner separation vortex captures the boundary-layer on the diffuser suction side. It then redirects the $\Omega_{x}$ vorticity component of the boundary-layer toward the blade-to-blade direction.

Another structure is also visible on the suction side of the diffuser vane. It corresponds to the tilt of the $\Omega_{x}$ vorticity generated at the diffuser leading-edge due to the high incidence on the diffuser vanes at near surge operating point. Then, the diffuser leading-edge vortex also contributes to the growth of the hub-corner separation.

Under the effect of the suction, the hub-corner separation growth is slowed down and the interaction with the impeller vortex shedding is decreased. In Figure 10(b), the tilt of the impeller trailing edge vortex is less than for the base case. With the three-slot suction case, in Figure 10(c), the interaction is further decreased, and this may be the explanation of 
the increase of stable operating range when the hub-corner separation is pushed downstream.

However, the role played by the diffuser leading-edge vortex is unchanged under the effect of the suction, and it now appears to be the main visible interaction that feeds the hubcorner separation. Further work should aim at gaining more understanding of the role played by this diffuser leadingedge vortex and its consequences for the surge inception. Controlling the development or the trajectory of this vortex could lead to a complete removal of the hub-corner separation.

\section{Conclusions and Outlooks}

According to the URANS numerical model, and at the nominal rotational speed, the three-slot suction strategy allows a significant increase of the centrifugal compressor operating range toward low mass flow rate. This demonstrates the interest of the boundary-layer suction technique in order to improve the performance of centrifugal compressor stages. It also confirms that the hub-corner separation in the diffuser is involved in the surge inception for the present test case.

The single-slot suction strategy allows delaying the hub-corner separation growth, and the three-slot strategy delays it further. As a consequence, the interaction between the hub-corner separation vortex and the impeller trailing edge vortex shedding is reduced, which is expected to be the key feature of the control of the surge. With the three-slot strategy, this interaction is almost cancelled, and this may explain the increase of the stable operating range.

The analysis has also revealed the interaction between the hub-corner separation and the diffuser leading-edge separation vortex, which should be taken into consideration in order to achieve a complete removal of the hub-corner separation. The leading-edge separation may be controlled by suction applied to the diffuser suction side, or by other control techniques as vortex generator, for example.

Finally, the interest of the multislot control strategy should also be challenged at other rotational speeds, and the issue of the optimal shapes of the suction slots should be addressed, prior to conducting experiments.

\section{Conflicts of Interest}

The authors declare that there are no conflicts of interest regarding the publication of this paper.

\section{Acknowledgments}

The authors would like to thank Turbomeca, Safran group, for providing the test case and supporting the present study. Thanks also are due to the ISAE laboratory at Université de Toulouse, where the experimental test rig is set up. Thanks are due to ONERA, which develops the elsA software and provides support regarding the numerical simulations.

\section{References}

[1] P. Came, "The current state of research and design in high pressure ratio centrifugal compressors," DTIC Document, 1976.

[2] C. Amann, G. Nordenson, and G. Skellenger, "Casing modification for increasing the surge margin of a centrifugal compressor in an automotive turbine engine," ASME, vol. 97, no. 3, pp. 329335, 1975.

[3] R. Hunziker and G. Gyarmathy, "Operational stability of a centrifugal compressor and its dependence on the characteristics of the subcomponents," Journal of Turbomachinery, vol. 116, no. 2, pp. 250-259, 1994.

[4] E. Greitzer, "The stability of pumping systems," Journal of Fluids Engineering, vol. 103, pp. 193-242, 1981.

[5] M. P. Wernet, M. M. Bright, and G. J. Skoch, "An investigation of surge in a high-speed centrifugal compressor using digital PIV," Journal of Turbomachinery, vol. 123, no. 2, pp. 418-428, 2001.

[6] J. N. Everitt, Investigation of stall inception in centrifugal compressors using isolated diffuser simulations [M.S. thesis], MIT Dept. Aero/Astro, 2010.

[7] J. N. Everitt and Z. S. Spakovszky, "An investigation of stall inception in centrifugal compressor vaned diffuser," Journal of Turbomachinery, vol. 135, Article ID 011025, 2012.

[8] R. A. Hill IV, Simulation of spike stall inception in a radial vanted diffuser [M.S. thesis], Massachusetts Institute of Technology, 2007.

[9] Y. Bousquet, X. Carbonneau, G. Dufour, N. Binder, and I. Trebinjac, "Analysis of the unsteady flow field in a centrifugal compressor from peak efficiency to near stall with full-annulus simulations," International Journal of Rotating Machinery, vol. 2014, Article ID 729629, 11 pages, 2014.

[10] Y. Bousquet, N. Binder, G. Dufour, X. Carbonneau, M. Roumeas, and I. Trebinjac, "Numerical simulation of stall inception mechanisms in a centrifugal compressor with vaned diffuser," Journal of Turbomachinery, vol. 138, no. 12, Article ID 121005, 2016.

[11] N. Buffaz and I. Trébinjac, "Aerodynamic instabilities in transonic centrifugal compressor," Mechanics and Industry, vol. 15, no. 3, pp. 191-196, 2014.

[12] I. Trébinjac, E. Benichou, and N. Buffaz, "Full-annulus simulation of the surge inception in a transonic centrifugal compressor," Journal of Thermal Science, vol. 24, no. 5, pp. 442-451, 2015.

[13] E. Benichou and I. Trébinjac, "Comparison of steady and unsteady flows in a transonic radial vaned diffuser," Journal of Turbomachinery, vol. 138, no. 12, Article ID 121002, 2016.

[14] E. Benichou and I. Trébinjac, "Numerical analysis of an alternate stall in a radial vaned diffuser," in ASME Turbo Expo 2016: Turbomachinery Technical Conference and Exposition, American Society of Mechanical Engineers, 2016.

[15] N. Fujisawa, S. Ikezu, and Y. Ohta, "Structure of diffuser stall and unsteady vortices in a centrifugal compressor with vaned diffuser," in ASME Turbo Expo 2016: Turbomachinery Technical Conference and Exposition, American Society of Mechanical Engineers, 2016.

[16] A. Merchant, J. L. Kerrebrock, J. J. Adamczyk, and E. Braunsheidel, "Experimental investigation of a high pressure ratio aspirated fan stage," American Society of Mechanical Engineers, pp. 493-502, 2004.

[17] B. J. Schuler, J. L. Kerrebrock, and A. Merchant, "Experimental investigation of a transonic aspirated compressor," Journal of Turbomachinery, vol. 127, no. 2, pp. 340-348, 2005. 
[18] S. A. Gbadebo, N. A. Cumpsty, and T. P. Hynes, "Control of three-dimensional separations in axial compressors by tailored boundary layer suction," Journal of Turbomachinery, vol. 130, no. 1, Article ID 011004, 2008.

[19] J. L. Kerrebrock, A. H. Epstein, A. A. Merchant et al., "Design and test of an aspirated counter-rotating fan," Journal of Turbomachinery, vol. 130, no. 2, Article ID 021004, 2008.

[20] A. Godard, F. Bario, S. Burguburu, and F. Lebuf, "Experimental and numerical study of a subsonic aspirated cascade," in ASME Turbo Expo 2012: Turbine Technical Conference and Exposition, pp. 253-267, American Society of Mechanical Engineers, 2012.

[21] K. K. Botros and J. F. Henderson, "Developments in centrifugal compressor surge control - a technology assessment," Journal of Turbomachinery, vol. 116, no. 2, pp. 240-249, 1994.

[22] J. Raw, "Surge margin enhancement by a porous throat diffuser," Canadian Aeronautics and Space Journal, vol. 32, no. 1, pp. 5461, 1986.

[23] E. B. Nelson, J. D. Paduano, and A. H. Epstein, "Active stabilization of surge in an axicentrifugal turboshaft engine," Journal of Turbomachinery, vol. 122, no. 3, pp. 485-493, 2000.

[24] G. J. Skoch, "Experimental investigation of centrifugal compressor stabilization techniques," Journal of Turbomachinery, vol. 125, no. 4, pp. 704-713, 2003.

[25] G. J. Skoch, "Experimental investigation of diffuser hub injection to improve centrifugal compressor stability," Journal of Turbomachinery, vol. 127, no. 1, pp. 107-117, 2005.

[26] Z. S. Spakovszky, "Backward traveling rotating stall waves in centrifugal compressors," Journal of Turbomachinery, vol. 126, no. 1, pp. 1-12, 2004.

[27] T. Halawa, M. S. Gadala, M. Alqaradawi, and O. Badr, "Optimization of the efficiency of stall control using air injection for centrifugal compressors," Journal of Engineering for Gas Turbines and Power, vol. 137, no. 7, Article ID 072604, 2015.

[28] H. Schönenborn, "Removal of cooling air on the suction side of a diffuser vane of a radial compressor stage of gas turbines," US Patent 6,210,104, April 2001.

[29] A. Leblanc, "Diffuser with enhanced surge margin," US Patent 8,556,573, October 2013.

[30] A. Marsan, I. Trébinjac, S. Coste, and G. Leroy, "Influence of unsteadiness on the control of a hub-corner separation within a radial vaned diffuser," Journal of Turbomachinery, vol. 137, no. 2, 12 pages, 2015.

[31] A. Marsan, I. Trébinjac, S. Coste, and G. Leroy, "Study and control of a radial vaned diffuser stall," International Journal of Rotating Machinery, vol. 2012, Article ID 549048, 12 pages, 2012.

[32] A. Marsan, I. Trébinjac, S. Coste, and G. Leroy, “Temporal behaviour of a corner separation in a radial vaned diffuser of a centrifugal compressor operating near surge," Journal of Thermal Science, vol. 22, no. 6, pp. 555-564, 2013.

[33] I. Trébinjac, P. Kulisa, N. Bulot, and N. Rochuon, "Effect of unsteadiness on the performance of a transonic centrifugal compressor stage," Journal of Turbomachinery, vol. 131, no. 4, Article ID 041011, 9 pages, 2009.

[34] N. Bulot and I. Trébinjac, "Effect of the unsteadiness on the diffuser flow in a transonic centrifugal compressor stage," International Journal of Rotating Machinery, vol. 2009, Article ID 932593, 11 pages, 2009.

[35] L. Cambier and J. P. Veuillot, "Status of the elsA CFD software for flow simulation and multidisciplinary applications," in Proceedings of the 46th AIAA Aerospace Science Meeting and Exhibit, vol. 664, Reno, Nev, USA, 2008.
[36] J. I. Erdos, E. Alzner, and W. McNally, "Numerical solution of periodic transonic flow through a fan stage," AIAA Journal, vol. 15, no. 11, pp. 1559-1568, 1977.

[37] J. M. Tyler and T. G. Sofrin, "Axial flow compressor noise studies," SAE International, vol. 70, Article ID 620532, 24 pages, 1962.

[38] G. A. Gerolymos, G. J. Michon, and J. Neubauer, "Analysis and application of chorochronic periodicity in turbomachinery rotor/stator interaction computations," Journal of Propulsion and Power, vol. 18, no. 6, pp. 1139-1152, 2002.

[39] L. Castillon, G. Billonnet, S. Péron, and C. Benoit, "Numerical simulations of technological effects encountered on turbomachinery configurations with the chimera technique," in Proceedings of 27th International Congress of the Aeronautical Sciences, Nice, France, September 2010.

[40] Y. Bousquet, X. Carbonneau, G. Dufour, N. Binder, and I. Trebinjac, "Analysis of the unsteady flow field in a centrifugal compressor from peak efficiency to near stall with full-annulus simulations," International Journal of Rotating Machinery, vol. 2014, Article ID e729629, 11 pages, 2014.

[41] Z. S. Spakovszky and C. H. Roduner, "Spike and modal stall inception in an advanced turbocharger centrifugal compressor," Journal of Turbomachinery, vol. 131, no. 3, Article ID 031012, 2009.

[42] P. Chakraborty, S. Balachandar, and R. J. Adrian, "On the relationships between local vortex identification schemes," Journal of Fluid Mechanics, vol. 535, pp. 189-214, 2005.

[43] J. C. Hunt, A. Wray, and P. Moin, "Eddies, streams, and convergence zones in turbulent flows," Tech. Rep. CTR-S88, Center for Turbulence Research, 1988. 


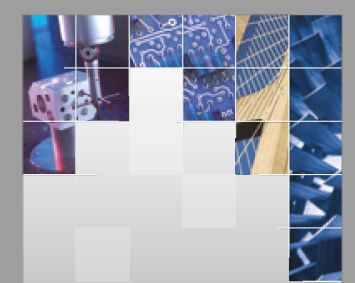

\section{Enfincering}
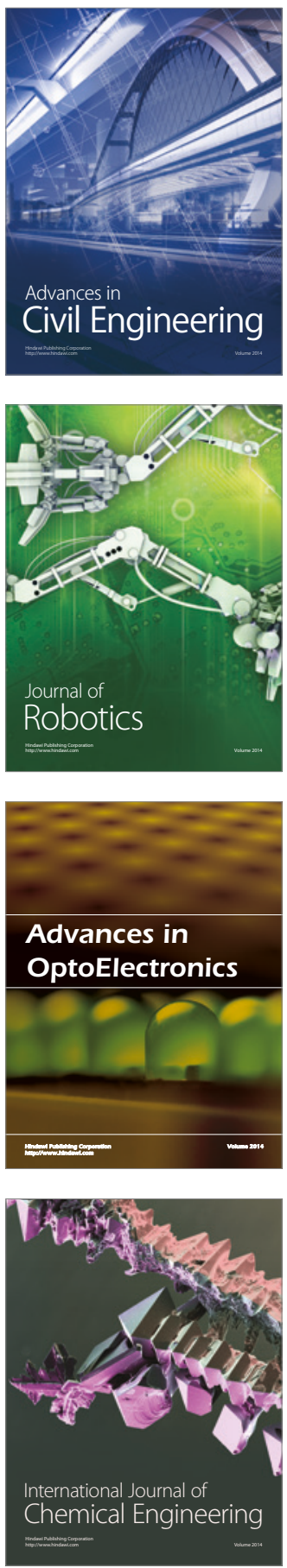

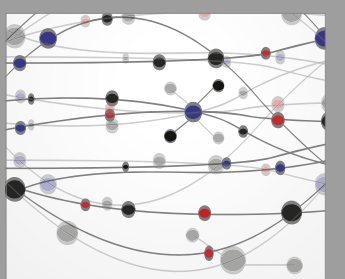

The Scientific World Journal

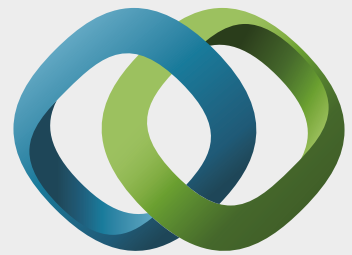

\section{Hindawi}

Submit your manuscripts at

https://www.hindawi.com
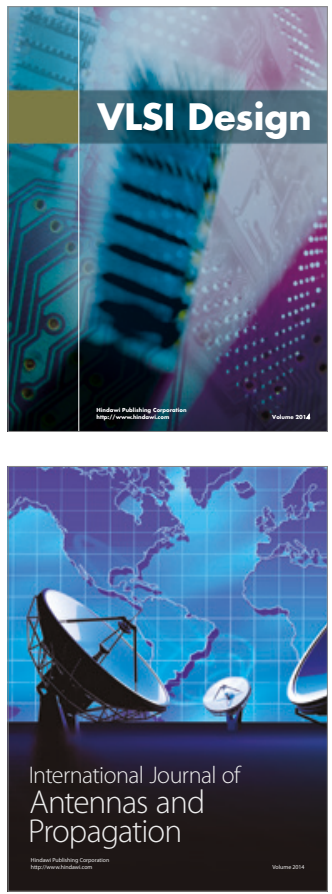

\section{Rotating}

Machinery
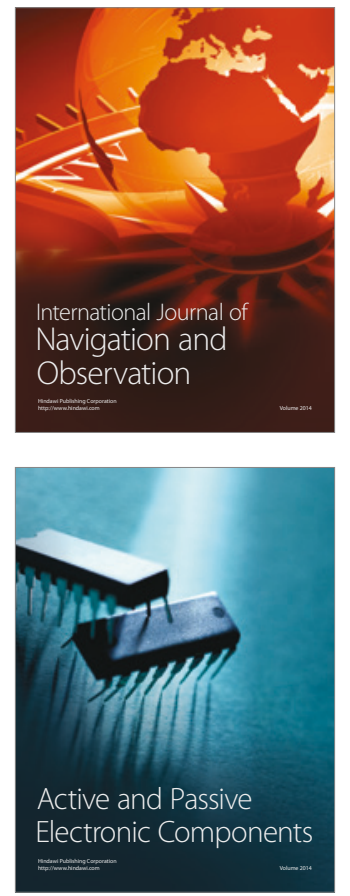
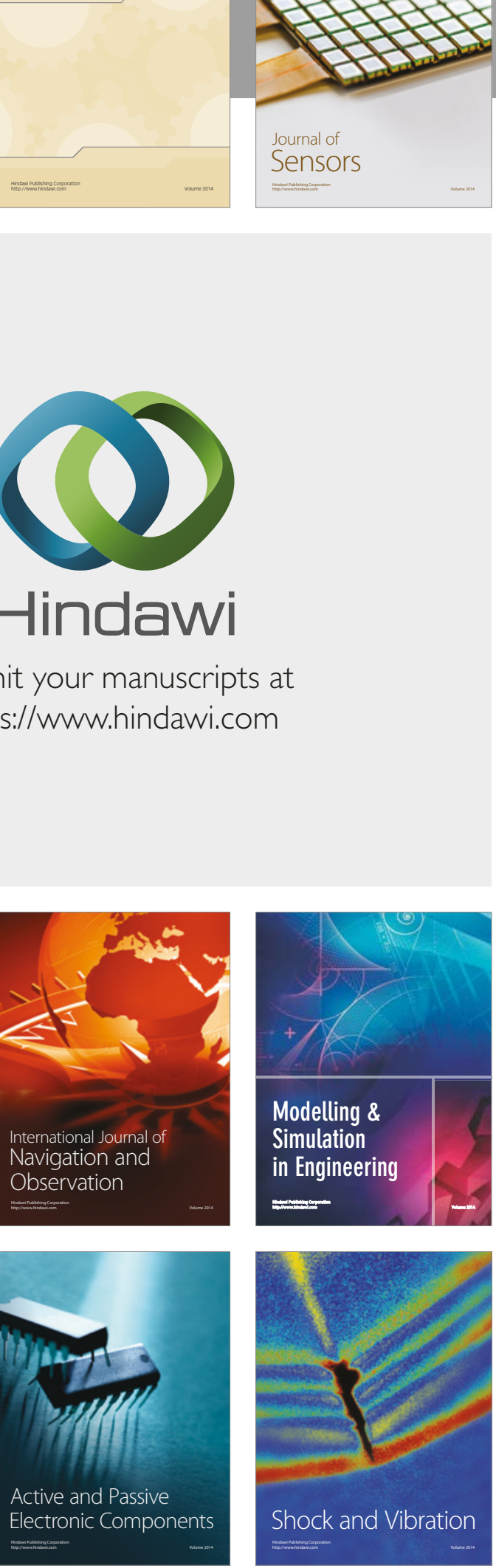
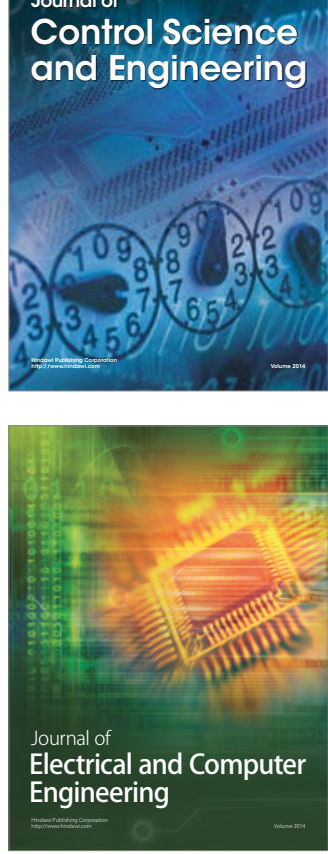

Distributed

Journal of

Control Science

and Engineering
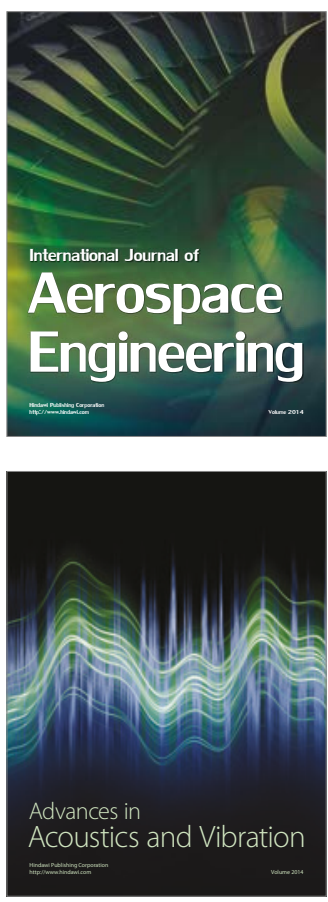

Sensor Networks 